\title{
(a)
}

Revista Agrarian

ISSN: $1984-2538$

\section{Efeito heterótico em características da carcaça e da carne de novilhos terminados em confinamento}

\section{Heterotic effect on carcass and meat characteristics from steers feedlot finished}

\author{
Jonatas Cattelam ${ }^{1 *}$, Ivan Luiz Brondani ${ }^{1}$, Dari Celestino Alves Filho ${ }^{1}$, João Restle ${ }^{2}$, Ana Paula \\ Machado Martini ${ }^{1}$, Patrícia Machado Martini ${ }^{1}$, Mauren Burin da Silva ${ }^{1}$, Camille Carijo Domingues ${ }^{1}$ \\ ${ }^{1}$ Universidade Federal de Santa Maria. Departamento de Zootecnia. Santa Maria - RS \\ ${ }^{2}$ Universidade Federal do Tocantins. Programa de Pós-graduação Ciência Animal Tropical. Araguaína - TO \\ *e-mail: jonatascattelam@yahoo.com.br
}

\begin{abstract}
Resumo
O presente estudo teve por objetivo avaliar o efeito heterótico sobre as características da carcaça e da carne de novilhos do cruzamento entre as raças Charolês $(\mathrm{Ch})$ e Nelore $(\mathrm{Ne})$ e cruzados entre essas raças de quinta $(21 / 32 \mathrm{Ch} 11 / 32 \mathrm{Ne} ; 21 / 32 \mathrm{Ne} 11 / 32 \mathrm{Ch})$ e sexta $(43 / 64 \mathrm{Ch} 21 / 64 \mathrm{Ne}$; $43 / 64 \mathrm{Ne} 21 / 64 \mathrm{Ch})$ gerações, terminados em confinamento. A dieta cotinha relação volumoso: concentrado de 39: 61 (base na matéria seca). Para o total de músculos na carcaça, o efeito heterótico foi significativo na quinta e sexta gerações, com valores de 14,7 e $15,8 \mathrm{~kg}$, e para os pesos de gordura e osso apenas na quinta geração, com valores de 5,90 e 4,49, citados na mesma ordem. Quando os tecidos foram expressos por $100 \mathrm{~kg}$ de carcaça fria, assim como para as relações entre os tecidos, o efeito heterótico não foi significativo em nenhuma das gerações do cruzamento. Entre os definidos, novilhos da raça Charolês foram superiores aos Nelore no total de músculo na carcaça (145,7 contra $116,0 \mathrm{~kg}$ ) e no percentual desse tecido na carcaça $(67,7$ e $62,2 \%)$, sendo que os animais zebuínos apresentaram maiores peso (41,7 e 37,9 kg) e participação de gordura na carcaça em relação aos taurinos (22,3 contra 17,5\%). Para as perdas de líquido, houve efeito heterótico para as perdas ao descongelar na quinta geração $(2,95 \%) \mathrm{e}$ para perdas ao cozimento na sexta geração $(-5,07 \%)$, porém para a perda total de líquidos e para as características organolépticas da carne não houve efeito heterótico em nenhuma das gerações. $O$ cruzamento entre bovinos das raças Charolês e Nelore produz novilhos com maior deposição de tecidos na carcaça, sem alterar as proporções entre esses, bem como não influencia a qualidade do produto cárnico.
\end{abstract}

Palavras-chave: gordura, heterose, maciez, marmoreio, músculo

\section{Summary}

The present study aimed to evaluate the heterotic effect on the carcass and meat characteristics of Charolais $(\mathrm{Ch})$ and Nelore $(\mathrm{Ne})$ crossbred steers and also crossbred steers from these two races of the fifth $(21 / 32 \mathrm{Ch}$ $11 / 32 \mathrm{Ne} ; 21 / 32 \mathrm{Ne} 11 / 32 \mathrm{Ch})$ and sixth $(43 / 64 \mathrm{Ch} 21 / 64 \mathrm{Ne} ; 43 / 64 \mathrm{Ne} 21 / 64 \mathrm{Ch})$ generation, finished in feedlot. The diet contained roughage: concentrate ratio of 39:61 (based on dry matter). For the total muscles in the carcass, the heterotic effect was significant on fifth and sixth generations, with values of 14.7 and15.8 $\mathrm{kg}$, and for the fat and bone weight the effect was significant only on fifth generation, with values of 5.90 and 4.49 cited on the same order. When the tissues were expressed by $100 \mathrm{~kg}$ of cold carcass, as well as the relation between tissues, there was no significant effect in any of the crossbred generations. Between the defined, Charolais steers were superior to Nelore steers on total muscles in the carcass $(145.7$ versus $116.0 \mathrm{~kg})$ and on the percentage of this tissue on the carcass (67.7 and 62.2\%), on the other hand the zebu animals presented heavier weight $(41.7$ and $37.9 \mathrm{~kg}$ ) and greater fat participation on the carcass in relation to the taurine animals (22.3 versus $17.5 \%)$. Regarding the liquid losses there was an heterotic effect for defrosting losses on fifth generation (2.95\%) and for cooking losses on sixth generation (-5.07\%), however there was no heterotic effect in any of the generations for the total liquid losses and for the organoleptic characteristics of the meat. The crossbreed between Charolais and Nelore generates steers with greater tissues deposition on the carcass, without changing the proportion between the tissues, as well as without influencing the quality of the meat product.

Key words: fat, heterosis, marbling, muscle, tenderness 


\section{(-) \\ Revista Agrarian \\ ISSN: 1984-2538}

\section{Introdução}

O Brasil destaca-se na produção de bovinos de corte, sendo detentor do maior rebanho comercial de bovinos e líder em exportação de carne bovina, porém com baixos índices de produtividade. Alves et al. (2005) ressaltam que a pecuária de corte nacional é um dos setores produtivos com maiores dificuldades para se organizar e superar obstáculos para manter e expandir seu mercado. Cattelam et al. (2009) relatam que o uso do confinamento acarreta em benefícios como aumento no ganho de peso, principalmente em épocas de restrição na qualidade e quantidade do pasto, além de benefícios na qualidade da carcaça e da carne de bovinos oriundos desse sistema de produção.

O cruzamento de bovinos das raças Charolês e Nelore visa combinar a rusticidade do zebuíno com características produtivas dos europeus, e explorar os efeitos de heterose originários do distanciamento genético entre $B o s$ taurus indicus e Bos taurus taurus (Koger, 1980). Prado et al. (2008) citam que o cruzamento entre raças bovinas permite buscar genótipos mais adequados ao seu sistema de produção e que atendam a demanda de mercado, principalmente quanto a qualidade de carcaça e carne.

De acordo com Costa et al. (2002) as etapas pelas quais o consumidor costuma avaliar a qualidade da carne são, em princípio, a cor do músculo e da gordura de cobertura, seguidas por aspectos envolvidos no processamento, como perda de líquidos no descongelamento e na cocção e, finalmente, são avaliadas as características de palatabilidade, suculência e a principal, que é a maciez.

Alguns estudos apontam que bovinos de raças europeias apresentam carne mais macia que zebuínos (Maggioni et al., 2012; Tizioto et al., 2014). Porém, ao avaliarem a qualidade da carne de bovinos cruzados, terminados em confinamento, Menezes et al. (2005) observaram melhora na qualidade da carne, com heterose positiva em todas gerações do cruzamento para maciez da carne, o que ressalva a possibilidade de incrementar a qualidade da carne com o cruzamento entre raças. Entretanto, na literatura ainda são poucos os estudos do efeito heterótico sobre a qualidade da carne, sobretudo em gerações avançadas do cruzamento entre raças bovinas. Desse modo, o presente estudo teve por objetivo avaliar o efeito heterótico sobre características da carcaça e qualidade da carne de novilhos oriundos do cruzamento entre as raças Charolês e Nelore, terminados em confinamento.

\section{Material e Métodos}

O presente estudo foi realizado no período de julho a novembro de 2010 no Laboratório de Bovinocultura de Corte pertencente ao Departamento de Zootecnia da Universidade Federal de Santa Maria, localizado no município de Santa Maria, na região fisiográfica da Depressão Central do estado do Rio Grande do Sul. Foram utilizados 48 novilhos, com idade e peso médio iniciais de 20 meses e $243,4 \mathrm{~kg}$, respectivamente. Os animais eram definidos das raças Charolês $(\mathrm{Ch})$ e Nelore $(\mathrm{Ne})$, e cruzados entre essas raças de quinta $(21 / 32 \mathrm{Ch} 11 / 32 \mathrm{Ne} ; 21 / 32 \mathrm{Ne} 11 / 32 \mathrm{Ch})$ e sexta $(43 / 64 \mathrm{Ch} \quad 21 / 64 \mathrm{Ne} ; 43 / 64 \mathrm{Ne} \quad 21 / 64 \mathrm{Ch})$ gerações.

Os animais foram confinados em baias coletivas, sendo essas parcialmente cobertas, providas de piso de alvenaria e comedouro de concreto com disponibilidade de $0,80 \mathrm{~m}$ por animal e bebedouro. Os novilhos permaneceram confinados por 112 dias até atingir condição adequada para o abate. A dieta com $11,5 \%$ de proteína bruta e $62 \%$ de nutrientes digestíveis totais, continha relação volumoso: concentrado de 39: 61 (base na matéria seca), sendo o volumoso utilizado a silagem de sorgo (Sorghum bicolor L Moench). O concentrado utilizado foi produto comercial, sendo $100 \mathrm{~kg}$ de matéria verde do mesmo composto por $42 \mathrm{~kg}$ de milho moído; 34,12 $\mathrm{kg}$ de farelo de arroz desengordurado; $12 \mathrm{~kg}$ de grão aveia branca moído; 7,38 kg de farelo de soja; $3,80 \mathrm{~kg}$ de calcário calcítico; $0,5 \mathrm{~kg}$ de cloreto de sódio e $0,2 \mathrm{~kg}$ de premix. Os animais foram alimentados à vontade duas vezes ao dia, ad libitum. A quantidade de alimento oferecido por dia foi regulada pelo consumo voluntário, procurandose manter sobras de 50 à $80 \mathrm{~g} / \mathrm{kg}$ da quantidade ofertada. Para tanto, as sobras eram retiradas diariamente antes da primeira alimentação, a fim de medir o consumo do dia anterior e ajustar a oferta do dia subseqüente. Os animais foram pesados no início do período experimental, e em intervalos de 21 dias, até o embarque para o frigorífico, sendo previamente submetidos a jejum de sólidos e líquidos por 14 horas.

Após atingir grau de acabamento adequado para comercialização, $3 \mathrm{~mm}$ de espessura de gordura de cobertura, os novilhos foram 


\section{(-) \\ Revista Agrarian \\ ISSN: 1984-2538}

submetidos a jejum de sólidos e líquidos de 14 horas, a fim de mensurar o peso de abate, sendo em seguida transportados para frigorífico comercial, localizado a $30 \mathrm{~km}$ da fazenda experimental, e abatidos seguindo fluxo do estabelecimento. Mais informações sobre as características da carcaça dos animais do presente estudo são apresentadas por Cattelam et al. (2014). Após resfriamento das carcaças por 24 horas foram realizadas as avaliações de marmoreio, cor e textura da carne, a partir da secção do músculo Longissimus dorsi na altura da $12^{\mathrm{a}}$ costela, conforme metodologia descrita por Müller (1987). Para determinar as porcentagens dos tecidos seguiu-se a metodologia de Hankins e Howe (1946) adaptada por Müller (1973).

A porção do músculo Longissimus dorsi extraída foi embalada e congeladas para posterior análise das características sensoriais. Das amostras, ainda congeladas, foram extraídas duas fatias de 2,5 cm de espessura. A fatia "A" foi pesada $\mathrm{e}$ descongelada, para determinação da quebra durante o processo de descongelamento, e cozida até atingir temperatura interna de $70^{\circ} \mathrm{C}$, para avaliação da quebra no processo de cocção da carne. Nessa mesma fatia, após o cozimento, foram retiradas cinco amostras de feixes de fibras com $1 \mathrm{~cm}^{3}$ de área, as quais foram cortadas no sentido perpendicular às fibras musculares, por intermédio do aparelho Warner-Bratzler Shear, para determinação da força de cisalhamento da carne. A fatia $\mathrm{B}$, depois de cozida de forma semelhante à fatia A, foi avaliada por um painel de cinco treinadores seguindo a metodologia de Müller (1987) quanto à maciez, palatabilidade e suculência.

$\mathrm{O}$ delineamento experimental foi $\mathrm{o}$ inteiramente casualizado, sendo cada novilho uma unidade experimental, com número diferente de repetições por grupo genético, sendo cinco animais do grupo $\mathrm{Ne}$; seis $43 / 64 \mathrm{Ne} 21 / 64 \mathrm{Ch}$; oito novilhos Ch; oito animais $43 / 64 \mathrm{Ch} 21 / 64 \mathrm{Ne}$; dez repetições para o grupo $21 / 32 \mathrm{Ch} 11 / 32 \mathrm{Ne}$ e 11 novilhos do genótipo $21 / 32 \mathrm{Ne} 11 / 32 \mathrm{Ch}$. Os dados foram submetidos a análise de variância pelo proc GLM, sendo o modelo matemático:

$$
\mathrm{Y}_{\mathrm{ij}}=\mu+\mathrm{GER}_{\mathrm{i}}+\mathrm{GG}_{\mathrm{j}}(\mathrm{GER})_{\mathrm{i}}+\varepsilon_{\mathrm{ij}}
$$

em que: $Y_{\mathrm{ij}}$ representa as variáveis dependentes; $\mu$ a média geral das observações; GER é a geração do cruzamento entre as raças Charolês (Ch) e Nelore $(\mathrm{Ne})$, sendo 1 (definidos); 5 (cruzados de quinta geração) e 6 (cruzados da sexta geração); GG representa o grupo genético do novilho, sendo 1 (Charolês) e 2 (Nelore) dentro da GER 1; 1 $(21 / 32 \mathrm{Ch} 11 / 32 \mathrm{Ne})$ e $2(21 / 32 \mathrm{Ne} 11 / 32 \mathrm{Ch})$ dentro da GER 5; $1(43 / 64 \mathrm{Ch} 21 / 64 \mathrm{Ne})$ e $2(43 / 64 \mathrm{Ne}$ $21 / 64 \mathrm{Ch})$ dentro da GER 6 ; $\varepsilon_{(\mathrm{i}) \mathrm{j} \mathrm{k}}$ o erro residual aleatório. As médias foram classificadas pelo teste "F" e os parâmetros com efeito significativo comparados pelo "teste t", com $\alpha=0,05$. As variáveis dependentes foram submetidas à análise de correlação de Pearson pelo procedimento proc CORR. As análises foram realizadas através do pacote estatístico SAS (Statistical Analysis System, versão 9.2).

\section{Resultados e Discussão}

Para o total de músculos na carcaça (Tabela 1), o efeito heterótico foi significativo na quinta e sexta gerações, com valores de 14,7 e 15,8 $\mathrm{kg}$, respectivamente, demonstrando que o uso do cruzamento é alternativa quando se busca elevar a quantidade desse tecido na carcaça. Segundo Luchiari Filho (2000) dos diferentes tipos de tecidos musculares que compõem a carne, o músculo esquelético é o mais valorizado em virtude da sua quantidade na carcaça e de seu maior valor econômico. Menezes et al. (2005) ao avaliarem as características da carcaça de novilhos de diferentes gerações do cruzamento entre as raças Charolês e Nelore, terminados em confinamento, observaram heteroses de 14,$48 ; 25,46$ e $21,76 \%$ na segunda, terceira e quarta gerações, respectivamente.

Para os pesos de gordura e osso houve efeito heterótico significativo apenas na quinta geração, com valores de 5,90 e 4,49, citados na mesma ordem. De outro modo, Menezes et al. (2005) encontraram heteroses significativas em todas as gerações do cruzamento entre as mesmas raças usadas no presente estudo para a quantidade de tecidos adiposo e ósseo. Restle et al. (2002) estudaram a composição física da carcaça de vacas de descarte das raças Charolês e Nelore e cruzadas $\mathrm{F} 1$ entre essas raças, terminadas em confinamento, e observaram heterose de $23,48 \%$ no peso de gordura na fêmeas de primeira geração. A gordura é um nutriente fundamental e também importante componente do sistema de produção de carne, pois a eficiência de produção, a precocidade, o acabamento da carcaça, os rendimentos de cortes, a maciez e a suculência do produto estão relacionados à quantidade e ao local de deposição de gordura (Berndt et al., 2002). 


\section{(-) \\ Revista Agrarian \\ ISSN: 1984-2538}

Dentro de cada geração do cruzamento, observa-se que entre os definidos, novilhos da raça Charolês foram superiores aos Nelore no total de músculo na carcaça $(145,7$ contra $116,0 \mathrm{~kg})$ e no percentual desse tecido na carcaça $(67,7$ e $62,2 \%)$, sendo que os animais zebuínos apresentaram maiores pesos (41,7 e $37,9 \mathrm{~kg})$ e participação de gordura na carcaça em relação aos taurinos (22,3 contra 17,5\%). Menezes et al. (2005) observaram através da análise de contrastes que a raça Charolês apresenta elevado efeito genético aditivo para deposição de tecido muscular na carcaça e maior potencial da raça Nelore para deposição de tecido adiposo. Perotto et al. (2000) também comprovaram a superioridade de bovinos da raça Charolês em características relacionadas a musculosidade da carcaça. Esses resultados ficam caracterizados aos se observar as diferenças entre novilhos cruzados e definidos, tendo os mestiços $30,1 \mathrm{~kg}$ a mais de músculo na carcaça que os Nelore, e 2,61\% a mais de gordura que os Charolês.

Tabela 1. Efeito heterótico e diferenças entre novilhos cruzados e definidos para pesos absolutos e participação dos tecidos em relação ao peso de carcaça fria (PCF) de novilhos de diferentes genótipos e gerações de cruzamento entre as raças Charolês e Nelore

\begin{tabular}{lcccccc}
\hline \multirow{2}{*}{ Grupo Genético } & \multicolumn{2}{c}{ Músculo } & \multicolumn{2}{c}{ Gordura } & \multicolumn{2}{c}{ Osso } \\
\cline { 2 - 7 } & $\mathrm{kg}$ & $\% \mathrm{PCF}$ & $\mathrm{kg}$ & $\% \mathrm{PCF}$ & $\mathrm{kg}$ & $\%$ PCF \\
\hline Charolês & $145,7 \pm 5,3 \mathrm{a}$ & $67,7 \pm 1,3 \mathrm{a}$ & $37,9 \pm 2,4 \mathrm{~b}$ & $17,5 \pm 1,8 \mathrm{~b}$ & $32,6 \pm 1,3$ & $15,1 \pm 0,5$ \\
Nelore & $116,0 \pm 6,9 \mathrm{~b}$ & $62,2 \pm 1,9 \mathrm{~b}$ & $41,7 \pm 3,6 \mathrm{a}$ & $22,3 \pm 2,7 \mathrm{a}$ & $29,0 \pm 2,0$ & $15,6 \pm 0,7$ \\
Média Definidos & $130,9 \pm 5,5$ & $65,0 \pm 1,2$ & $39,9 \pm 2,2$ & $19,9 \pm 0,8$ & $30,8 \pm 1,2$ & $15,4 \pm 0,4$ \\
& & & & & & \\
21/32Ch 11/32Ne & $149,7 \pm 5,5$ & $64,6 \pm 1,2$ & $47,3 \pm 2,2$ & $20,4 \pm 2,5$ & $35,5 \pm 1,2$ & $15,3 \pm 0,4$ \\
21/32Ne 11/32Ch & $141,4 \pm 5,3$ & $63,9 \pm 1,1$ & $44,2 \pm 2,1$ & $20,1 \pm 3,7$ & $35,1 \pm 1,1$ & $16,0 \pm 0,4$ \\
Média G5 & $145,6 \pm 3,8$ & $64,2 \pm 0,8$ & $45,8 \pm 1,5$ & $20,2 \pm 0,5$ & $35,3 \pm 0,8$ & $15,7 \pm 0,3$ \\
Efeito heterótico G5 & $14,7 \pm 6,7^{*}$ & $-0,74 \pm 1,4$ & $5,90 \pm 2,6^{*}$ & $0,33 \pm 0,9$ & $4,49 \pm 1,4 *$ & $0,29 \pm 0,5$ \\
& & & & & & \\
43/64Ch 21/64Ne & $148,1 \pm 6,9$ & $66,0 \pm 1,5$ & $45,5 \pm 2,7$ & $20,3 \pm 1,6$ & $31,8 \pm 1,5$ & $14,2 \pm 0,5$ \\
43/64Ne 21/64Ch & $145,1 \pm 8,1$ & $64,9 \pm 1,7$ & $43,9 \pm 3,3$ & $19,8 \pm 2,0$ & $34,6 \pm 1,8$ & $15,4 \pm 0,6$ \\
Média G6 & $146,7 \pm 5,3$ & $65,5 \pm 1,1$ & $44,8 \pm 2,1$ & $20,1 \pm 0,7$ & $33,2 \pm 1,1$ & $14,9 \pm 0,4$ \\
Efeito heterótico G6 & $15,8 \pm 7,6^{*}$ & $0,51 \pm 1,6$ & $4,91 \pm 3,1$ & $0,17 \pm 1,1$ & $2,40 \pm 1,7$ & $-0,51 \pm 0,6$ \\
Diferenças & & & & & & \\
Cruzados e Ch & $0,36 \pm 6,9$ & $-2,88 \pm 1,5$ & $7,31 \pm 2,7 *$ & $2,61 \pm 1,0 *$ & $1,66 \pm 1,5$ & $0,11 \pm 0,5$ \\
Cruzados e Ne & $30,1 \pm 9,7^{*}$ & $2,65 \pm 2,1$ & $3,50 \pm 3,9$ & $-2,11 \pm 2,8$ & $5,24 \pm 2,1 *$ & $-0,33 \pm 0,8$ \\
\hline
\end{tabular}

$\overline{a, b}$ Médias seguidas por letras diferentes na mesma geração diferem com $\mathrm{P}<0,05$ pelo teste " $t$ " de Student $* \mathrm{P}<0,05$

Quando os diferentes tecidos foram expressos por $100 \mathrm{~kg}$ de carcaça fria, o efeito heterótico não foi significativo em nenhuma das gerações do cruzamento, concordando com os resultados observados por Menezes et al. (2005). Também Perotto et al. (2000) ao estudarem as características da carcaça de bovinos das raças Charolês e Caracu e oriundos de seu cruzamento recíproco, terminados em confinamento, não observaram heterose significativa nos animais de segunda e terceira geração para o percentual de tecidos na carcaça.

Para as proporções entre os diferentes tipos de tecidos (Tabela 2), não houve efeito heterótico significativo em nenhuma das gerações avaliadas, sendo que apenas entre os novilhos definidos, animais da raça Charolês apresentaram maior relação entre os tecidos muscular e adiposo que os bovinos definidos da raça Nelore, o que demonstra o potencial da raça na produção de carne magra. A carne bovina, do ponto de vista nutricional, é alimento de alto valor, pois sua composição em aminoácidos essenciais, lipídios, vitaminas e sais minerais são adequados à alimentação humana, sendo principalmente, fonte proteica, em função de ter entre seus componentes maior proporção de fibras musculares (Costa et al., 2002). Para Pacheco et al. (2005) é relevante estudar a relação entre os tecidos adiposo e muscular em virtude da atual preocupação mundial com a ingestão de gordura e seus possíveis reflexos negativos sobre a saúde humana, agravados pelo sedentarismo e pela falta de exercícios. 


\section{(-) \\ Revista Agrarian \\ ISSN: 1984-2538}

Tabela 2. Efeito heterótico e diferenças entre novilhos cruzados e definidos para relações entre os diferentes tecidos que compõem a carcaça de novilhos de diferentes genótipos e gerações de cruzamento entre as raças Charolês e Nelore

\begin{tabular}{lccc}
\hline \multirow{2}{*}{ Grupo Genético } & \multicolumn{3}{c}{ Relações entre os tecidos } \\
\cline { 2 - 4 } & Músculo/ Osso & Músculo/ Gordura & (Músculo + Gordura)/ Osso \\
\hline Charolês & $4,47 \pm 0,17$ & $3,90 \pm 0,18 \mathrm{a}$ & $5,63 \pm 0,18$ \\
Nelore & $3,99 \pm 0,25$ & $2,83 \pm 0,27 \mathrm{~b}$ & $5,43 \pm 0,28$ \\
Média Definidos & $4,23 \pm 0,15$ & $3,37 \pm 0,16$ & $5,53 \pm 0,17$ \\
& & & \\
21/32Ch 11/32Ne & $4,24 \pm 0,15$ & $3,22 \pm 0,16$ & $5,58 \pm 0,17$ \\
21/32Ne 11/32Ch & $4,08 \pm 0,14$ & $3,30 \pm 0,16$ & $5,33 \pm 0,16$ \\
Média G5 & $4,16 \pm 0,10$ & $3,26 \pm 0,11$ & $5,45 \pm 0,11$ \\
Efeito heterótico G5 & $-0,07 \pm 0,18$ & $-0,11 \pm 0,20$ & $-0,07 \pm 0,20$ \\
& & & \\
43/64Ch 21/64Ne & $4,68 \pm 0,19$ & $3,27 \pm 0,21$ & $6,11 \pm 0,21$ \\
43/64Ne 21/64Ch & $4,21 \pm 0,23$ & $3,31 \pm 0,25$ & $5,49 \pm 0,25$ \\
Média G6 & $4,44 \pm 0,15$ & $3,29 \pm 0,16$ & $5,80 \pm 0,16$ \\
Efeito Heterótico G6 & $0,21 \pm 0,21$ & $-0,08 \pm 0,23$ & $0,27 \pm 0,23$ \\
Diferenças & & & \\
Cruzados e Ch & $-0,17 \pm 0,19$ & $-0,63 \pm 0,21 *$ & $-0,01 \pm 0,21$ \\
Cruzados e Ne & $0,31 \pm 0,27$ & $0,44 \pm 0,30$ & $0,20 \pm 0,29$ \\
\hline
\end{tabular}

${ }_{\mathrm{a}, \mathrm{b}}$ Médias seguidas por letras diferentes na mesma geração diferem com $\mathrm{P}<0,05$ pelo teste " $\mathrm{t}$ " de Student $* \mathrm{P}<0,05$

Também nas diferenças entre cruzados e definidos, os mestiços apresentam relação 0,63 inferior aos definidos da raça Charolês, o que demonstra o ímpeto dessa raça taurina continental na deposição de tecido muscular, conforme anteriormente discutido. De acordo com Owens et al. (1995), a idade, a condição fisiológica, a condição sexual, o estádio de maturidade, o peso corporal, o nível nutricional, a raça, o estado hormonal e as condições ambientais são os principais fatores que influenciam a taxa de crescimento e a composição física da carcaça.

De acordo com Berg \& Butterfield (1976), dos tecidos que compõem a carcaça o muscular é o mais importante, pois é o mais procurado pelo consumidor. Assim, a carcaça deve ter quantidade máxima de músculos, mínima de osso e quantidade de gordura conforme a preferência do consumidor. Esses mesmos autores ressaltam que o tecido ósseo apresenta maiores taxas de crescimento nos animais em estágio mais jovem, seguido pelo crescimento do tecido muscular, enquanto o tecido adiposo é acumulado em estágios mais avançados de desenvolvimento, porém é depositado em todas as idades desde que o consumo de nutrientes, principalmente energia, exceda os requerimentos de mantença e crescimento (Boggs \& Merkel, 1981). Assim, a elevada participação de concentrado, $61 \%$ da matéria seca da dieta, permitiu que esses apresentassem adequada deposição de gordura, com valores próximos aos relatados por Pacheco et al. (2005), Vaz et al. (2005) e Silveira et al. (2009) que estudaram características da carcaça de bovinos com composição genética semelhante e idade de idade de abate próxima a deste estudo, também confinados.

A cor da carne (Tabela 3) não foi influenciada pela raça bem como pela geração do cruzamento, sendo a coloração da carne classificada como "vermelha". Do mesmo modo, a textura avaliada pela granulação das fibras musculares, foi classificada como "fina". Esses resultados devem estar relacionados a similaridade na dieta dos animais, na idade ao abate e no fato das práticas de manejo empregadas serem as mesmas para todos animais. Do mesmo modo, Restle et al. (2002) não observaram efeito da heterose sobre as características acima citadas na carne de vacas de descarte e novilhos, respectivamente, de primeira geração do cruzamento entre as raças Charolês e Nelore.

De acordo com Müller (1987), a cor da carne não altera seu valor organoléptico, porém é um fator importante na comercialização, uma vez que o consumidor rejeita a carne com coloração mais escura, por associá-la com animais mais velhos ou com má conservação da carne. Com 


\section{(-) \\ Revista Agrarian \\ ISSN: 1984-2538}

relação a textura, embora hajam pesquisas que indicam que, quando se aumenta o grau de sangue zebuíno no genótipo de uma raça taurina, a textura da carne torna-se mais grosseira (Restle et al., 2002), há também estudos (Vaz et al., 2014) que demonstram que a textura da carne não é alterada pela inclusão da raça Nelore no genótipo dos bovinos, quando esses são terminados em confinamento e abatidos em idade precoce.

Tabela 3. Efeito heterótico e diferenças entre novilhos cruzados e definidos para cor, textura e marmoreio, em pontos e por $100 \mathrm{~kg}$ de carcaça fria, de novilhos de diferentes genótipos e gerações de cruzamento entre as raças Charolês e Nelore

\begin{tabular}{lcccc}
\hline \multirow{2}{*}{ Grupo Genético } & \multirow{2}{*}{ Cor, pontos } & Textura, pontos & \multicolumn{2}{c}{ Marmoreio } \\
\cline { 3 - 5 } & $4,22 \pm 0,33$ & $4,44 \pm 0,24$ & $3,22 \pm 0,46$ & $1,49 \pm 0,18$ \\
Charolês & $3,50 \pm 0,49$ & $3,75 \pm 0,36$ & $2,50 \pm 0,70$ & $1,31 \pm 0,28$ \\
Nelore & $3,86 \pm 0,30$ & $4,09 \pm 0,21$ & $2,86 \pm 0,42$ & $1,40 \pm 0,17$ \\
Média Definidos & & & \\
& $3,81 \pm 0,30$ & $4,09 \pm 0,21$ & $3,45 \pm 0,42$ & $1,47 \pm 0,17$ \\
21/32Ch 11/32Ne & $4,00 \pm 0,28$ & $4,08 \pm 0,21$ & $3,75 \pm 0,40$ & $1,65 \pm 0,16$ \\
21/32Ne 11/32Ch & $3,91 \pm 0,20$ & $4,08 \pm 0,15$ & $3,60 \pm 0,29$ & $1,56 \pm 0,11$ \\
Média G5 & $0,05 \pm 0,36$ & $-0,01 \pm 0,26$ & $0,74 \pm 0,51$ & $0,15 \pm 0,20$ \\
Efeito heterótico G5 & & & & \\
& $3,71 \pm 0,37$ & $4,00 \pm 0,27$ & $3,28 \pm 0,53$ & $1,46 \pm 0,21$ \\
43/64Ch 21/64Ne & $4,00 \pm 0,44$ & $4,60 \pm 0,32$ & $2,40 \pm 0,62$ & $1,07 \pm 0,25$ \\
43/64Ne 21/64Ch & $3,85 \pm 0,29$ & $4,30 \pm 0,21$ & $2,84 \pm 0,41$ & $1,27 \pm 0,16$ \\
Média G6 & $-0,01 \pm 0,41$ & $0,20 \pm 0,30$ & $-0,02 \pm 0,58$ & $-0,13 \pm 0,23$ \\
Efeito Heterótico G6 & & & \\
Diferenças & $-0,33 \pm 0,37$ & $-0,25 \pm 0,27$ & $0,01 \pm 0,52$ & $-0,08 \pm 0,21$ \\
Cruzados e Ch & $0,38 \pm 0,52$ & $0,44 \pm 0,38$ & $0,72 \pm 0,74$ & $0,10 \pm 0,29$ \\
Cruzados e Ne &
\end{tabular}

${ }^{1} 1=$ muito grosseira; $2=$ grosseira; $3=$ levemente grosseira; $4=$ fina; $5=$ muito fina

${ }^{2} 1$ = escura; $2=$ vermelho-escura; $3=$ vermelho levemente escura; $4=$ vermelha; $5=$ vermelho vivo

${ }^{3} 1$ a $3=$ traços; 4 a $6=$ leve; 7 a $9=$ pequeno; 10 a $12=$ médio; 13 a $15=$ moderado; 16 a $18=$ abundante

Para o marmoreio, que representa a gordura intramuscular, não houve efeito heterótico em nenhuma das gerações, assim como dentro de cada geração não houve diferença entre os genótipos, tanto expresso em pontos como em relação a $100 \mathrm{~kg}$ de carcaça fria. Também Restle et al. (2002) e Menezes et al. (2005) não observaram heterose sobre a marmorização da carne. Semelhança na marmorização da carne de novilhos de genótipo Charolês ou Nelore é relatada por Cattelam et al. (2009) e Silveira et al. (2009). Rodrigues et al. (2008) observaram que à medida que o grau de sangue zebuíno aumentou no genótipo, a marmorização da carne diminuiu, informação corroborada por Marshall (1994), o qual cita que o aumento da participação do genótipo Bos taurus indicus reduz a marmorização da carne e piora a maciez da carne. Os resultados do presente estudo demonstram que a raça Nelore pode ser utilizada no cruzamento com a raça Charolês, sem prejudicar a marmorização da carne.

Para as perdas de líquidos durante o preparo das carnes, representadas pelas perdas nos processos de descongelamento e cocção (Tabela 4), houve efeito heterótico para as perdas ao descongelar na quinta geração $(2,95 \%)$ e para perdas ao cozimento na sexta geração $(-5,07 \%)$, porém para a perda total de líquidos não houve efeito heterótico em nenhuma das gerações. Vaz et al. (2001) e Menezes et al. (2005) ao avaliarem a qualidade da carne de novilhos de distintas gerações do cruzamento entre as raças Charolês e Nelore, terminados em confinamento e abatidos aos 24 meses, não observaram efeito da heterose sobre as perdas de líquidos aos descongelar ou a coç̧ão. 


\section{(-) \\ Revista Agrarian \\ ISSN: 1984-2538}

Tabela 4. Efeito heterótico e diferenças entre novilhos cruzados e definidos para perdas de líquidos por evaporação e gotejamento, ao descongelar e a cocção, da carne de novilhos de diferentes genótipos e gerações de cruzamento entre as raças Charolês e Nelore

\begin{tabular}{lccc}
\hline \multirow{2}{*}{ Grupo Genético } & \multicolumn{3}{c}{ Perdas, $\%$} \\
\cline { 2 - 4 } & Descongelamento & Cocção & Total \\
\hline Charolês & $5,23 \pm 0,96$ & $24,3 \pm 1,76$ & $29,5 \pm 1,97$ \\
Nelore & $8,43 \pm 1,45$ & $29,7 \pm 2,64$ & $38,1 \pm 2,95$ \\
Média Definidos & $6,83 \pm 0,87$ & $27,0 \pm 1,59$ & $33,8 \pm 1,77$ \\
& & & \\
21/32Ch 11/32Ne & $9,23 \pm 0,87$ & $23,3 \pm 1,59$ & $32,6 \pm 1,78$ \\
21/32Ne 11/32Ch & $10,3 \pm 0,83$ & $25,2 \pm 1,52$ & $35,5 \pm 1,71$ \\
Média G5 & $9,78 \pm 0,60$ & $24,2 \pm 1,10$ & $34,0 \pm 1,23$ \\
Efeito heterótico G5 & $2,95 \pm 1,06^{*}$ & $-2,74 \pm 1,93$ & $0,21 \pm 2,16$ \\
& & & \\
43/64Ch 21/64Ne & $8,45 \pm 1,09$ & $22,1 \pm 2,00$ & $30,5 \pm 2,23$ \\
43/64Ne 21/64Ch & $8,27 \pm 1,29$ & $21,8 \pm 2,37$ & $30,0 \pm 2,64$ \\
Média G6 & $8,36 \pm 0,84$ & $21,9 \pm 1,55$ & $30,3 \pm 1,73$ \\
Efeito Heterótico G6 & $1,52 \pm 1,21$ & $-5,07 \pm 2,22^{*}$ & $-3,54 \pm 2,48$ \\
Diferenças & & & \\
Cruzados e Ch & $3,84 \pm 1,10^{*}$ & $-1,23 \pm 2,00$ & $2,61 \pm 2,24$ \\
Cruzados e Ne & $0,64 \pm 1,53$ & $-6,58 \pm 2,81^{*}$ & $-5,94 \pm 3,14$ \\
\hline
\end{tabular}

$\overline{a, b}$ Médias seguidas por letras diferentes na mesma geração diferem com $\mathrm{P}<0,05$ pelo teste " $\mathrm{t}$ " de Student $* \mathrm{P}<0,05$

Para as características organolépticas da carne (Tabela 5), não houve efeito heterótico em nenhuma das gerações avaliadas, com valores para essas características classificados como acima da média. Esses resultados observados no presente estudo demonstram que o uso de novilhos das raças Charolês e Nelore, bem como cruzados entre essas raças não altera as características sensoriais da carne quando os animais são terminados em confinamento alimentados com elevada participação de concentrado, sendo que neste estudo correspondeu a $61 \%$ da matéria seca da dieta. Conforme French et al. (2000) o valor comercial da carne de bovinos alimentados com dietas de elevada participação de concentrado é maior que daqueles de dietas ricas em volumosos, principalmente pela diferença na sua qualidade. Segundo revisão de Boleman et al. (1996) a alimentação de animais no período de terminação com dieta de elevada densidade energética favorecem as características sensoriais da carne, inclusive a maciez, em função da rápida síntese de proteínas, aumentando a proporção de colágeno solúvel na carne. Conforme Ito et al. (2012) a terminação de animais jovens confinados é possível através do uso de dietas de alta densidade energética, o que assegura maiores taxas de ganho de peso produzem carnes de melhor maciez, pois o rápido crescimento muscular propicia a formação de colágeno de maior solubilidade. No presente estudo, na média, os animais apresentaram ganho médio diário de peso de $1,37 \mathrm{~kg}$.

Tabela 5. Efeito heterótico e diferenças entre novilhos cruzados e definidos para características organolépticas e força de cisalhamento da carne de novilhos de diferentes genótipos e gerações de cruzamento entre as raças Charolês e Nelore

\begin{tabular}{lcccc}
\hline Grupo Genético & $\begin{array}{c}\text { Suculência, } \\
\text { pontos }^{1}\end{array}$ & $\begin{array}{c}\text { Palatabilidade, } \\
\text { pontos }^{1}\end{array}$ & $\begin{array}{c}\text { Maciez, } \\
\text { pontos }^{1}\end{array}$ & $\begin{array}{c}\text { Força de cisalhamento, } \\
\mathrm{kgF} / \mathrm{cm}^{3}\end{array}$ \\
\hline Charolês & $6,65 \pm 0,23$ & $6,77 \pm 0,19$ & $7,48 \pm 0,33$ & $4,35 \pm 0,43$ \\
Nelore & $6,13 \pm 0,34$ & $6,02 \pm 0,29$ & $5,84 \pm 0,49$ & $5,93 \pm 0,65$ \\
Média Definidos & $6,39 \pm 0,20$ & $6,39 \pm 0,17$ & $6,66 \pm 0,29$ & $5,14 \pm 0,39$ \\
& & & & \\
$21 / 32 \mathrm{Ch} 11 / 32 \mathrm{Ne}$ & $6,33 \pm 0,21$ & $6,34 \pm 0,18$ & $6,64 \pm 0,29$ & $5,27 \pm 0,39$ \\
$21 / 32 \mathrm{Ne} 11 / 32 \mathrm{Ch}$ & $6,57 \pm 0,20$ & $6,45 \pm 0,18$ & $6,38 \pm 0,28$ & $5,52 \pm 0,37$ \\
Média G5 & $6,45 \pm 0,14$ & $6,39 \pm 0,12$ & $6,51 \pm 0,20$ & $5,39 \pm 0,27$ \\
Efeito heterótico G5 & $0,05 \pm 0,25$ & $0,00 \pm 0,21$ & $-0,15 \pm 0,35$ & $0,25 \pm 0,47$ \\
\hline
\end{tabular}




\section{Revista Agrarian}

ISSN: 1984-2538

\begin{tabular}{lcccc} 
43/64Ch $21 / 64 \mathrm{Ne}$ & $6,40 \pm 0,26$ & $6,40 \pm 0,22$ & $6,95 \pm 0,37$ & $4,82 \pm 0,49$ \\
43/64Ne 21/64Ch & $6,48 \pm 0,31$ & $6,31 \pm 0,26$ & $6,87 \pm 0,44$ & $4,49 \pm 0,58$ \\
Média G6 & $6,44 \pm 0,20$ & $6,35 \pm 0,17$ & $6,91 \pm 0,28$ & $4,66 \pm 0,38$ \\
Efeito Heterótico G6 & $0,04 \pm 0,29$ & $-0,03 \pm 0,24$ & $0,25 \pm 0,41$ & $-0,48 \pm 0,55$ \\
Diferenças & & & & \\
Cruzados e Ch & $-0,21 \pm 0,26$ & $-0,39 \pm 0,22$ & $-0,77 \pm 0,37^{*}$ & $0,67 \pm 0,49$ \\
Cruzados e Ne & $0,31 \pm 0,36$ & $0,35 \pm 0,31$ & $0,87 \pm 0,52$ & $-0,90 \pm 0,69$ \\
\hline
\end{tabular}

$* \mathrm{P}<0,05$

${ }^{1} 1$ = extremamente dura, extremamente sem sabor ou extremamente sem suculência; $2=$ muito dura, deficiente em sabor ou deficiente em suculência; 3 = dura, pouco saborosa ou pouco suculenta; 4 = levemente abaixo da média; 5 = média; 6 = levemente acima da média; 7 = macia, saborosa ou suculenta;

8 = muito macia, muito saborosa ou muito suculenta; 9 = extremamente macia, extremamente saborosa ou extremamente suculenta.

A similitude para suculência está associada a semelhança na perda de líquidos, com correlação entre essa e a perdas a cocção de $r=-0,29$ $(\mathrm{P}=0,0412)$. Correlação negativa entre as perdas de líquidos e a suculência é reportada por Arboitte et al. (2004). Para Lawrie (2005) a suculência tem como principais componentes a água liberada no início da mastigação e a gordura, que tem efeito estimulatório na salivação.

Os valores próximos de palatabilidade estão relacionados ao grau de marmorização, sendo que essa esteve associada ao marmoreio $(\mathrm{r}=0,36$; $\mathrm{P}=0,0115)$ e ao marmoreio expresso por $100 \mathrm{~kg}$ de carcaça fria $(\mathrm{r}=0,34 ; \mathrm{P}=0,0159)$. Resultado que corrobora com os observados por Costa et al. (2002), os quais citam que a deposição de gordura intramuscular está intimamente associada as características sensoriais da carne passíveis de serem percebidas e apreciadas pelo consumidor, sendo que esses observaram alta associação entre marmoreio e palatabiliddade $(\mathrm{r}=0,56 ; \mathrm{P}=0,0043)$, o que indica que a gordura tem substâncias flavorizantes agradáveis ao paladar.

Também a similaridade para maciez da carne o que deve estar associado à semelhança no total de perdas de líquidos durante o preparo das carnes, sendo observada correlação entre a maciez $\mathrm{e}$ as perdas de líquidos a cocção $(\mathrm{r}=-0,30$; $\mathrm{P}=0,0353)$ e a perda total de líquidos $(\mathrm{r}=-0,35$; $\mathrm{P}=0,0137$ ), demonstrando também que maiores perdas de líquidos durante o preparo das carnes diminuem a maciez. Outro aspecto associado a semelhança na maciez é a proximidade da idade de abate, visto das evidências que a qualidade organoléptica da carne, principalmente maciez piora com avanço da idade.
Para a força de cisalhamento não houve efeito heterótico em nenhuma das gerações avaliadas, bem como entre os genótipos dentro de cada geração do cruzamento, com valor médio de $5,06 \mathrm{kgF} / \mathrm{cm}^{3}$. Similaridade na força de cisalhamento entre bovinos de predomínio racial Charolês ou Nelore é reportada por Restle et al. (2002), os quais não observaram efeito da heterose sobre a força de cisalhamento da carne de vacas de descarte terminadas em confinamento. Os valores observados neste estudo estão próximos ao limiar descrito por Lawrie (2005), os quais citam que carnes com força de cisalhamento acima de 5,00 $\mathrm{kgF} / \mathrm{cm}^{3}$ caracterizam a carne como dura. Wheeler et al. (1994) buscaram estabelecer o efeito do grau de marmoreio sobre a maciez e força de cisalhamento na carne de genótipos Bos taurus indicus e Bos taurus taurus, observando que nos zebuínos o aumento do grau de marmoreio é mais importante para melhorar a maciez da carne e diminuir a força de cisalhamento, que nos genótipos europeus.

A falta de efeito heterótico para as características organolépticas também deve estar associada ao fato dessas serem de alta herdabilidade, sendo que a seleção de reprodutores com melhor valor genético para essas características implica na produção de bovinos com melhor qualidade de carne. A não observância de efeito heterótico sobre as características organolépticas da carne concorda com os resultados observados por Vaz et al. (2001) para novilhos definidos e mestiços oriundos do cruzamento entre as mesmas raças utilizadas neste estudo. Embora Restle et al. (2003) alertem que a maciez da carne diminua com a inclusão de sangue zebuíno no cruzamento, Wheeler et al. (1996) citam que os efeitos heteróticos das raças zebuínas 


\section{(a) \\ Revista Agrarian \\ ISSN: 1984-2538}

sobre a qualidade da carcaça são positivos e a queda de maciez da carne em animais cruzados é de pouca magnitude e importância prática. Outro fator que deve ter influenciado sobre a inobservância de efeito heterótico foi a qualidade da dieta ofertada, com elevada participação de concentrado, visto que a heterose tende a se manifestar de maneira mais pronunciada quando os bovinos são mantidos sob condições adversas.

As oportunidades de expansão do mercado de carne bovina estão intimamente associadas à capacidade competitiva do setor produtivo e, nesse aspecto, a qualidade é ponto fundamental (Alves et al., 2005). De acordo com Arboitte et al. (2004) para que a carne bovina seja mais produtiva em relação as carnes de aves e suínos, as quais tem um rigoroso controle de qualidade, é necessário investir em aspectos qualitativos, com destaque as características sensoriais, para agradar os consumidores do mercado interno e competir no mercado externo. De acordo com Paz \& Luchiari Filho (2000), dentre as características de qualidade da carne bovina, a maciez assume posição de destaque, sendo considerada como a característica organoléptica de maior influência na aceitação da carne por parte dos consumidores.

\section{Conclusões}

O cruzamento entre bovinos das raças Charolês e Nelore produz novilhos com maior deposição de tecidos na carcaça, sem alterar as proporções entre esses, bem como não influencia a qualidade do produto cárnico.

\section{Referências Bibliográficas}

ALVES, D.D.; GOES, R.H.T.B.; MANCIO, A.B. Maciez da carne bovina. Ciência Animal Brasileira, v.6, n.3, p.135-149, 2005.

ARBOITTE, M.Z.; RESTLE, J. ALVES FILHO, D.C.; PASCOAL, L.L.; PACHECO, P.S.; SOCCAL, D.C. Composição física da carcaça, qualidade da carne e conteúdo de colesterol no músculo Longissimus dorsi de novilhos 5/8 Nelore - 3/8 Charolês terminados em confinamento e abatidos em diferentes estádios de maturidade. Revista Brasileira de Zootecnia, v.33, n.4, p.959968, 2004.

BERG, R.T.; BUTTERFIELD, R.M. New concepts of cattle growth. Sydney: Sydney University Press, 1976. 240p.
BERNDT, A.; ALMEIDA, R.; LANNA, D.P. Importância da gordura na eficiência de produção, qualidade da carne e saúde do consumidor. In: ENCONTRO NACIONAL DO NOVILHO PRECOCE, 7., 2002, Cuiabá. Anais... Cuiabá: 2002.1 CD.

BOGGS, D.L.; MERKEL, R.A. Live animal: Carcass evaluation and selection manual. Ames: Michigan State University, 1981. 199p.

BOLEMAN, S.J.; MILLER, R.K.; BUYCK, M.J. Influence of realimentation of mature cows on maturity, color, collagen solubility, and sensory characteristics. Journal of Animal Science, v.74, p.2187-2194, 1996.

CATTELAM, J.; MENEZES, L.F.G.; FERREIRA, J.J.; RESTLE, J.; BRONDANI, I.L.; ARBOITTE, M.Z.; PAULA, P.C. Composição física da carcaça e qualidade da carne de novilhos e vacas de descarte de diferentes grupos genéticos submetidos a diferentes frequências de alimentação. Ciência Animal Brasileira, v.10, n.3, p.764-775, 2009.

CATTELAM, J; BRONDANI, I.L.; PACHECO, P.S.; ALVES FILHO. D.C.; PAULA, P.C.; AZEVEDO JÚNIOR, R.L.; RODRIGUES, L.S.; COCCO, J.M. Efeito heterótico sobre as características da carcaça de novilhos confinados. Revista Agrarian, v.7, n.24, p.328, 338, 2014.

COSTA, E.C.; RESTLE, J.; VAZ, F.N.; ALVES FILHO, D.C.; BERNARDES, R.A.L.C.; KUSS, F. Características da carcaça de novilhos Red Angus superprecoces abatidos com diferentes pesos. Revista Brasileira de Zootecnia, v.31, p.417-428, 2002. (suplemento).

CROUSE, J.D.; CUNDIFF, L.V.; KOCH, R.M.; KOOHMARIE, M.; SEIDMAN, S.C. et al. Comparisons of Bos indicus and Bos Taurus inheritance for carcass beef characteristics and meat palatability. Journal of Animal Science, v.67, n.9, p.2661-2668, 1989.

DeROUEN, S.M.; FRANKE, D.E.; BIDNER, T.D.; BLOUIN, D.C. Direct and maternal genetic effects for carcass traits in beef cattle. Journal of Animal Science, v.70, n.12, p.3677-3685, 1992

FRENCH, P.; O'RIORDAN, E.G.; MONAHAN, F.J.; CAFFREY, P.J.; VIDAL, M.; MOONEY, M.T.; TROY, D.J.; MOLONEY, A.P. Meat quality of steers finished on autumn grass, grass silage or 


\section{(-) \\ ISSN: 1984-2538}

Revista Agrarian

concentrate-based diets. Meat Science, v.56, p.173-180, 2000.

ITO, R.H.; VALERO, M.V.; PRADO, R.M.; RIVAROLI, D.C.; PEROTTO, D.; PRADO, I.N. Meat quality from four genetic groups of bulls slaughtered at 14 months old. Acta Scientiarum. Animal Sciences, v.34, n.4, p. 425-432, 2012.

KOGER, M. Effective crossbreeding systems utilizing zebu cattle. Journal of Animal Science. v.50, p.1213-1220, 1980.

LAWRIE, R.A. Ciência da carne. 6.ed. Porto Alegre: Artmed, 2005. 384p.

LUCHIARI FILHO, A. Pecuária da carne bovina. São Paulo: Luchiari Filho, 2000. 135p.

MAGGIONI, D.; PRADO, I.N.; ZAWADZKI, F.; VALERO, M.V.; MARQUES, J.A.; BRIDI, A.M.; MOLETTA, J.L.; ABRAHÃO, J.J.S. Grupos genéticos e graus de acabamento sobre a qualidade da carne de bovinos. Semina: Ciências Agrárias, v.33, n.1, p.391-402, 2012.

MARSHALL, D.M. Breed differences and genetic parameters for body composition traits in beef cattle. Journal of Animal Science, v.72, n.10, p.2745-2755, 1994.

MENEZES, L.F.G.; RESTLE, J.; BRONDANI, I.L.; ALVES FILHO, D.C.; KUSS, F.; SILVEIRA, M.F.; AMARAL, G.A. Composição física da carcaça e qualidade da carne de novilhos de gerações avançadas do cruzamento alternado contínuo entre as raças Charolês e Nelore, terminados em confinamento. Revista Brasileira de Zootecnia, v.34, n.3, p.946-956, 2005.

MÜLLER, L. Técnicas para determinar la composición de la canal. Memoria de La Asociación Latinoamericana de Producción Animal, p.75, 1973.

MÜLLER, L. Normas para avaliação de carcaças e concurso de carcaça de novilhos. 2 .ed. Santa Maria: Universidade Federal de Santa Maria, 1987.31p.

OWENS, F.N.; GILL, D.R.; SECRIST, D.S.; COLEMAN, S.W. Review of some aspects of growth and development of feedlot cattle. Journal of Animal Science, v.73, p.3152-3172, 1995.

PACHECO, P.S.; RESTLE, J.; SILVA, J.H.S.; BRONDANI, I.L.; PASCOAL, L.L.; ALVES FILHO, D.C.; ARBOITTE, M.Z.; FREITAS, A.K.
Composição física da carcaça e qualidade da carne de novilhos jovens e superjovens de diferentes grupos genéticos. Revista Brasileira de Zootecnia, v.34, n.5, p.1691-1703, 2005.

PAZ, C.C.P.; LUCHIARI FILHO, A. Melhoramento genético e diferenças de raças com relação à qualidade da carne bovina. Pecuária de Corte, n.101, p.58-63, 2000.

PEROTTO, D.; MOLETTA, J.L.; CUBAS, A.C. Características quantitativas da carcaça de bovinos Charolês, Caracu e cruzamentos recíprocos terminados em confinamento. Revista Brasileira de Zootecnia, v.29, n.1, p.117-124, 2000.

PRADO, I.N.; PRADO, R.M.; ROTTA, P.P.; VISENTAINER, J.V.; MOLETTA, J.L.; PEROTTO, D. Carcass characteristics and chemical composition of the Longissimus muscle of crossbred bulls (Bos taurus indicus vs Bos taurus taurus) finished in feedlot. Journal of Animal Feed Science, v. 17, p. 295-306, 2008.

RESTLE, J.; PASCOAL. L.L.; FATURI, C.; ALVES FILHO, D.C.; BRONDANI, I.L.; PACHECO, P.S.; PEIXOTO, L.A.O. Efeito do grupo genético e da heterose na composição física da carcaça e nas características qualitativas da carcaça e da carne de vacas de descarte terminadas em confinamento. Revista Brasileira de Zootecnia, v.31, n.3, p.1378-1387, 2002.

RESTLE, J.; VAZ, F. N.; BERNARDES, R.A.L. C.; PASCOAL, L.L.; MENEZES, L.F.G.; PACHECO, P.S. Características de carcaça e da carne de vacas de descarte de diferentes genótipos Charolês $\mathrm{x}$ Nelore, terminadas em confinamento. Ciência Rural, v.33, n.2, p.345-350, 2003.

RODRIGUES, E.; ARRIGONI, M.B.; JORGE, A.M.; BIANCHINI, W.; HADLICH, J.C.; MOREIRA, P.S.A.; MARTINS, C.L. Características físicas e químicas da carne de novilhas de diferentes grupos genéticos no modelo biológico superprecoce. Revista Brasileira de Saúde e Produção Animal, v.9, n.3, p. 594-604, 2008

SHORTHOSE, W. R.; HARRIS, P. V. Effects of growth and composition on meat quality. In: Growth regulation in farm animals (Advances in meat research). London: Elsevier Applied Science, 1991. p. 515-555. 


\section{(2) \\ Revista Agrarian \\ ISSN: 1984-2538}

SILVEIRA, M.F.; BRONDANI, I.L; ARBOITTE, M.Z.; ALVES FILHO, D.C.; RESTLE, J.; PIZZUTI, L.A.D.; LUZ, T.R.R.; RETORE, M. Composição física da carcaça e qualidade da carne de novilhos Charolês e Nelore que receberam diferentes proporções de concentrado na dieta. Arquivo Brasileiro de Medicina Veterinária e Zootecnia, v.61, n.2, p.467-474, 2009.

TIZIOTO, P.C.; GROMBONI, C.F.; NOGUEIRA, A.R.A.; SOUZA, M.M.; MUDADU, M.A.; THOLON, P.; ROSA, A.N.; TULLIO, R.R.; MEDEIROS, S.R.; NASSU, R.T.; REGITANO, L.C.A. Calcium and potassium content in beef: Influences on tenderness and associations with molecular markers in Nellore cattle. Meat Science, v.96, p.436-440, 2014.

VAZ, F.N.; RESTLE, J.; FEIJÓ, G.L.D.; BRONDANI, I.L.; ROSA, J.R.P.; SANTOS, A.P. Qualidade e composição química da carne de bovinos de corte inteiros ou castrados de diferentes grupos genéticos Charolês x Nelore. Revista Brasileira de Zootecnia, v.30, n.2, p.518-525, 2001.

VAZ, F.N.; RESTLE, J.; SILVA, N.L.Q.; ALVES FILHO, D.C.; PASCOAL, L.L.; BRONDANI, I.L.; KUSS, F. Nível de concentrado, variedade da silagem de sorgo e grupo genético sobre a qualidade da carcaça e da carne de novilhos confinados. Revista Brasileira de Zootecnia, v.34, n.1, p.239-248, 2005.

VAZ, F.N.; RESTLE, J.; FLORES, J.L.C.; PACHECO, P.S.; ÁVILA, M.M.; PASCOAL, L.L.; VAZ, R.Z.; VAZ, M.A.B. Qualidade da carcaça e da carne de bovinos superjovens de diferentes grupos genéticos. Revista Agrarian, v.7, n.24, p.319-327, 2014.

WHEELER, T.L.; CUNDIFF, L.V.; KOCH, R.M. Effect of marbling degree on beef palatability in Bos taurus and Bos indicus cattle. Journal of Animal Science, v.72, n.12, p.3145-3151, 1994.

WHEELER, T.L., CUNDIFF, L.V., KOCH, R.M. Characterization of biological types of cattle (Cycle IV): carcass traits and longissimus palatability. Journal of Animal Science, v.74, n.5, p.1023-1035, 1996. 